EESTI NSV TEADUSTE AKADEEMIA TOIMETISED. 23. KOIDE KEEMIA * GEOLOOGIA. 1974, NR. 3

ИЗВЕСТИЯ АКАДЕМИИ НАУК ЭСТОНСКОИ ССР. ТОМ 23 ХИМИЯ - ГЕОЛОГИЯ. 1974, № 3

УДК $551.7(474)$

А. БРАНГУЛИС, Э. КАЛА, А. МАРДЛА, Кайса МЕНС, Э. ПИРРУС, B. САКАЛАУСКАС, Ария ФРИДРИХСОНЕ, Т. ЯНКАУСКАС

\title{
СХЕМА СТРУКТУРНО-ФАЦИАЛЬНОГО РАЙОНИРОВАНИЯ ТЕРРИТОРИИ ПРИБАЛТИКИ В ВЕНДЕ И КЕМБРИИ
}

Вскрытые в течение последних десятилетий мнопочисленными скважинами разрезы вендских и кембрийских отложений Прибалтики во многом изменили представление о ходе геологического развития северо-западной окраины Восточно-Европейской платформы в начальные стадии ее существования. Обработка кернового материала этих скважин показала, что унифицироваюная региональная стратиграфическая схема верхнедокембрийских и кембрийских отложений северо-запада платформы, выработанная в основном на основании разрезов Северной Эстонии и Ленинградской области, не применима для большей части территории Прибалтики. Это привело к составлению для ее южных и центральных районов нескольких местных стратиграфических схем (Сакалаускас, 1966; Лиелдиена, Фридрихсоне, 1968; Биркис и др., 1970 и др.), область применения которых обычно определялась административными или даже ведомственными границами.

В целях дальнейшего усовершенствования и унификации стратиграфических схем для всех палеозойских отложений регнона Прибалтийская РМСК рекомендовала в 1971-1976 гг, провести работы в следующие три этапа: структурно-фацнальное районирование территории Прибалтики по крупным подразделениям геологической шкалы (по системам), разработка местных стратиграфнческих схем для выделенных структурно-фациальных районов; ооставление корреляционной стратиграфической схемы Прибалтики на базе местных схем.

Настоящая статья представляет собой результат работы вендо-кембрийской рабочей группы верхнепротерозойско-силурийской секции Прибалтийской РМСК по первому этапу исследования, в ходе которого были совместно пересмотрены за 1972 - 1973 гг. нанболее представительные разрезы венда и кембрия Прибалтики с целью установления типовых разрезов и оконтуривания районов, требующих разработки своих местных схем.

Территория Советской Прибалтики как часть Северо-Запада Восточно-Европейской платформы сложена древнейшими осадочными образованиями фанерозоя и отчасти криптозоя. По современному рельефу кристаллического фундамента на этой площади выделяются следующие четыре структуры крупного порядка: полого погружающийся на юг южный склон Балтийского щита; Латвийская седловина; Прибалтийская впадина, и северный склон Белорусско-Мазурского выступа. Қак показывают имеющиеся данные по распространению, мощности, составу и фациальному облику отложений осадочного чехла, эти основные структуры современного фундамента в какой-то степени имелись уже и в вендское, и в кембрийское время, определяя во многом конфигурации бассейнов осадконакопления и областей сноса, а также основные трансгрессивно-регрессивные изменения в субширотном направлении. 
В отличие от более поздних периодов древнего палеозоя, когда на территории Прибалтики длительное время существовал более или менее единый, открытый на запад бассейн карбонатонакопления, в вендское и кембрийское время здесь сменилось друг за другом не менее трех отдельных бассейнов, различающихся между собой как по направленности трансгрессии, так и по занимаемой площади и основному формацнонно-геохимическому режиму осадконакопления. Это было обусловлено прежде всего асинхронностью тектонического развития территории в широтном направлении. Так, на первых этапах формирования осадочного чехла - в валдайское и балтийское время - прогибалась в основном только восточная часть Прибалтики. В середине раннего кемб́рия происходило существенное изменение структурного плана: восточная часть территории стала постепенно подниматься, а западная - погружаться. Вследствие этого здесь сформировалась новая субмеридионально ориентированная и открытая на запад впадина - Балтийская синеклиза, которая стала основной областью осадконакопления для всех последующих периодов древнего палеозоя (рис. 1,5 и $B$ ). Несколько обособленно ведет себя только субширотная полоса вдоль современного северного побережья Эстонии, которая во время трансгрессии как с востока (валдайский и балтийский этапы), так и с запада (холмиевый этап) была сравнительно мобильной зоной опускания, вследствие чего образования бассейнов обоих направлений трансгрессии налагались здесь друг на друга (рис. $1, A)$.

Эти крупные перестройки морских бассейнов сопровождались большими перерывами в осадконакоплении, которые в разрезах отдельных частей территории занимали основную часть шкалы времени и обусловили тем самым неполноту разреза. Поэтому в целях структурно-фациального районирования пришлось для венда и кембрия учесть прежде всего фациальный признак наивысшего ранга - распределение по территории континентальных и морских фациальных обстановок, т. е. исходить из степени стратиграфической полноты разреза. Палеогеографические и фациальные особенности осадконакопления внутри отдельных бассейнов, которые в терригенных отложениях не всегда устанавливаются легко из-за трудностей точного сопоставления отдельных разрезов между собой, могут быть привлечены здесь только для выделения районов второго порядка (подрайонов) в пределах более узкого интервала геологического времени. Әтим вендо-кембрийский период отличается от систем с монобассейновым развитием осадконакопления (ордовик, силур), где фациально-палеогеографический признак может быть взят в качестве главного при районировании всей территории (Мянниль, 1966).

В вендском этапе по стратиграфической полноте разреза в пределах Прибалтики выделяются два района первого ранга (субрегиона), для которых целесообразно выработать свои местные схемы расчленения разреза (рис. 2).

Первый из них - Западно-Прибалтийский район - охватывает западную часть Прибалтики, где отложения венда либо отсутствуют, либо встречаются только в виде пятен на ограниченных плошадях (Курземский полуостров). Отнесение этих образований именно к венду весьма условно, так как стратиграфия их недостаточно разработана. Поэтому в настоящее время трудно установить для данного района даже типовой разрез.

Второй район - Восточно-Прибалтийский - занимает северо-восточную часть Литвы, восточную половину Латвии и в виде субширотного ответвления охватывает почти всю северную материковую часть Эстонии. Вендские отложения в этом районе распространены повсеместно и 
относятся в основном к валдайской серии, которая состоит здесь из трех весьма обособленных свит: гдовской, котлинской и воронковской (Менс, Пиррус, 1971). Только на юго-востоке Литвы в пределах ограниченной площади выделены еще мяркисская и яшюнайская свиты, относимые в настоящее время к волынской серии (Сакалаускас, 1968; Григялис и др., 1971). Судя по литологическому характеру мяркисской свиты (отсутствие слоистости, плохая отсортированность материала), площадь рассматриваемого участка была сначала зоной накопления континентальных отложений временных потоков и лишь начиная со второй половины волынского времени здесь возник бассейн постоянного осадконакопления, который в валдайское время расширился на весь район. Дальнейшая детализация стратиграфии валдайских отложений может быть осуществлена сугубо по фациальным признакам.

В качестве типовых разрезов венда на данной территории предлагаются скв. Вилькишкяй-68 в интервале $355,0-527,7$ м (кернохранилище Вильнюс), скв. Аа в интервале 111,2 - 215,5 м (кернохранилище Пюсси) и скв. Лудза-15 в интервале $797,0-913,6$ м (кернохранилище Рига).

Кембрийские отложения в Прибалтике в отличие от вендских имеют повсеместное распространение. Они отсутствуют только в сводах нескольких небольших локальных структур (Локно, Мынисте, Палукюла, Плунге) и на узкой полосе юго-востока Литвы (склон Белорусско-Мазурской антеклизы), но это отнюдь не препятствует выделению к настоящему времени трех областей с одинаковой геологической историей развития.

Северо-Прибалтийский район охватывает северную и центральную материковую часть Эстонии (рис. 3), где мощность отложений выдерживается в пределах $80-100$ м. Разрез состоит здесь из дотрилобитовых слоев кембрия (балтийская серия) и низов трилобитовых слоев (холмиевая серия). В балтийское время осадконакопление развивалось здесь по унаследованному от валдайского времени структурному плану: бассейн седиментации представлял собой, очевидно, заливообразный, открытый к востоку водоем. В начале второй половины раннего кембрия рассматриваемая территория была покрыта морем, открытым уже к западу. Более верхние подразделения сводного разреза кембрия Прибалтики в этом районе не представлены. К западу постепенно появляются черты Западно-Балтийского типа разреза. При этом наблюдается закономерное опесчанивание к западу дотрилобитовой части разреза, ввиду чего теряются установленные на востоке критерии для ее расчленения на более мелкие подразделения. В этом же направлении верхняя часть разреза дополняется более молодыми слоями раннего кембрия. Все это делает ограничение района на западе весьма условным. В настоящее время за границу нами принято появление в верхах разрезов глинистых отложений, покрывающих типичные тискреские алевролиты. Юго-восточный контур также не особенно ясен, но в какой-то степени он контролируется северным склоном Локновско-Мынистеского поднятия, ограничивающим Восточно-Прибалтийский район с севера. Кембрийские отложения Северо-Прибалтийского района в настоящее время исследованы лучше других. По современным представлениям (Мардла и др., 1968; Менс, Пиррус, 1971,1972 ; и др.), кембрийский разрез подразделяется здесь на лонтоваскую, люкатискую и тискрескую свиты. Типовым разрезом служит сводный разрез стратотипических обнажений отдельных подразделений (Тискре, Какумяги, Люкати и Кунда), который в обнажениях Кунда и Люкати дополнен керном скважин (кернохранилище Пюсси).

Западно-Прибалтийский район охватывает западные части трех республик и всю Калининградскую область. Характеризуется он наиболь- 


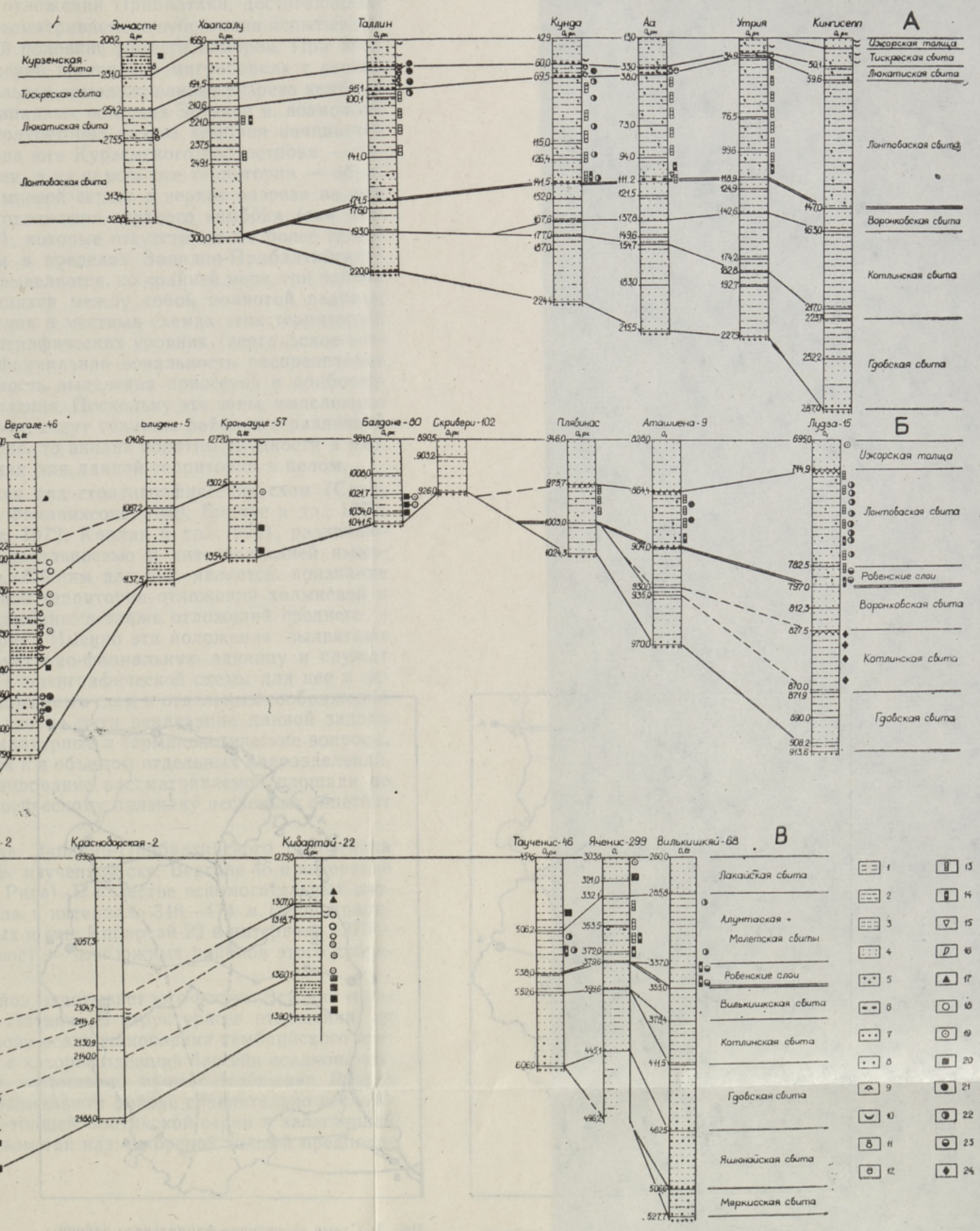

ис. 1. Геологические разрезы субширотного направления: $A-$ Эстония, $E$ - Латвия, $B$ - Қалининградская область и Литва. Расположение скважин

Об́означения: 1 - глины, 2 - чередование глин и алевролитов, 3 - алевролиты, $4-$ песчаники, 5 - породы кристаллического фундамента, $6-$ гальки фосфатизированных пород, 7 - оолиты бурого железняка, 8 - глауконит, 9 - трилобиты, 10 - брахиоподы, 11 - фораминиферы, 12 - вольбортеллы, фосфатизированных пород, - сабисоленитиды, $14-$ салелидитиды, 15 - хиолиты, 16 - тореллеллиды, $17-24-$ комплексы акритарх: $17-$ дейменский, $18-$ кибартайский, 19 - раусвенский, 20 - вергальский, 21 - люкатиский, 22 - лонтоваский, 23 - ровенский, $24-$ котлинский. 


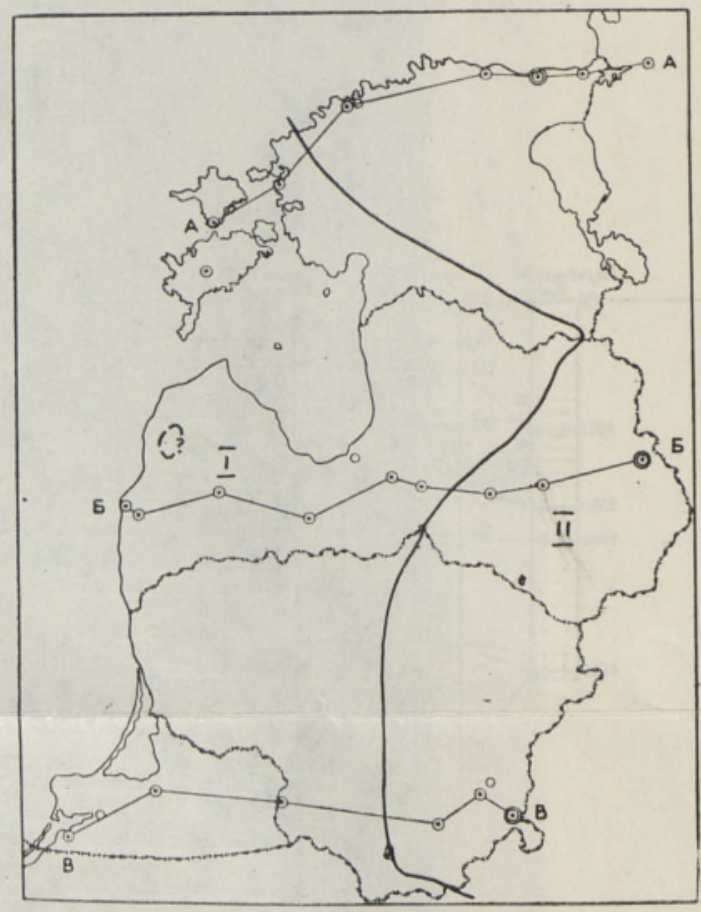

Рис. 2. Схема структурно-фациального районирования территории Прибалтики в венде: I Западно-Прибалтийский район, II - ВосточноПрибалтийский район, $A A, \bar{Б}, B B$ - линии геологических разрезов (крупными кружками указаны типовые разрезы).

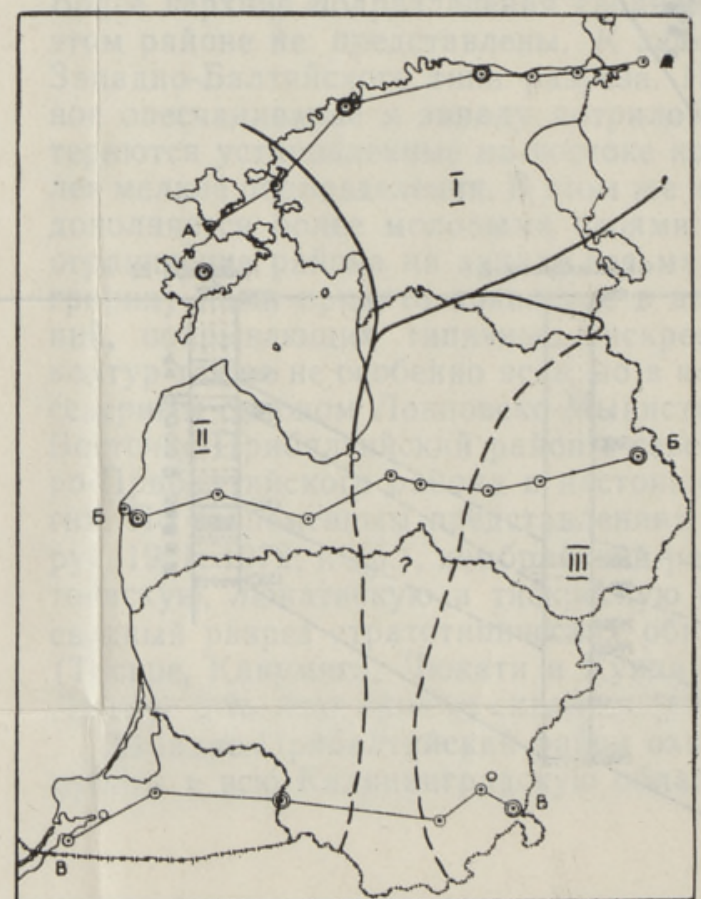

Рис. 3. Схема структурно-фациального районирования территории Прибалтики в кембрии: I - Северо-Прибалтийский район, II - Западно-Прибалтийский район, III - Восточно-Прибалтийский район, $A A, \overline{ }$, $B B$ - линии геологических разрезов (крупными кружками указаны типовые разрезы). 
шими мощностями кембрийских отложений Прибалтики, достигающими здесь местами 200 м. Площадь рассматриваемого субрегиона испытывала интенсивное погружениє во второй половине раннего кембрия. При этом осевая зона наибольших погружений постепенно мигрировала с севера на юг, обусловливая последовательное «омолаживание» разреза кембрия в том же направлении. Так, на западных островах Эстонии и, возможно, в северной части Курземского полуострова разрез кембрия начинается отложениями балтийской серии, на юге Курземского полуострова - базальными слоями холмиевой серии, а на самом юте территории - образованиями второй половины холмиевой серин; в верхах разреза на юге данного района участвуют уже отложения верхнего кембрия (скв. Ладушкино-1) (Каплан и др., 1973), которые отсутствуют на более северных площадях. В связи с этим в пределах Западно-Прибалтийского структурно-фациального района выделяется, по крайней мере, три района более низкого ранга, различающихся между собой полнотой разреза, что вызывает некоторые отклонения в местных схемах этих территорий. Кроме того, на отдельных стратиграфических уровнях (вергальское время) отмечается весьма четкая фашиальная зональность распределения отложений, что создает возможность выделения приосевой и прибортовой частей бассейна осадконакопления. Поскольку эти зоны, выделенные уже по узкофациальному признаку, секут границы районов с различной полнотой разреза перпендикулярно, то вполне понятны трудности в разработке единой схемы расчленения для данной территории в целом.

В настоящее время предложен ряд стратиграфических схем (Сакалаускас, 1966, 1968: Лиелдиена, Фрипоихсоне, 1968; Биркис и др., 1970; Григялис и др., 1971; Янкаускас, 1972; Каплан и др., 1972), различающихся между собой подходом, детальностью и интерпретацией имеющегося фактического материала. Общим для них является признание наличия в разрезе кембрия данной территории отложений холмиевой и протоленусовой серий раннего кембрия, а также отложений среднего, и на самом юге - верхнего кембрия. Именно эти положения выдвигают этот район в обособленную структурно-фациальную единицу и служат основой для разработки единой стратиграфической схемы для нее в целом. Не вдаваясь в детали предложенных схем и отдельных соображений исследователей, отметим лишь, что на пути реализации данной задачи предстоит решить многие номенклатурные и терминологические вопросы, связанные как с приоритетом. так и с объемом отдельных подразделений. Можно надеяться, что подрайонирование рассматриваемой плошади по фациальному или историко-геологическому признаку несколько облегчит эту задачу.

В качестве типового разреза Западно-Прибалтийского субрегиона нами предлагается керн наиболее изученной скв. Вергале-46 в интервале 1160 - 1379 м (кернохранилише Рига). В качестве вспомогательных разрезов можно отметить скв. Эйкла в интервале $348-474$ м (кернохранилише Насва) для самых северных и скв. Кибартай-22 в интервале 12751390 м (кернохранилище Вильнюс) - для южных районов этого субрегиона.

Восточно-Прибалтийский район охватывает юго-восток Эстонии и самые восточные части Литвы и Латвии. В структурном отношении он продолжает с запада крупную зону осадконакопления кембрийского времени - Московскую синеклизу, с которой здешний бассейн осадконакопления в балтийское время имел, несомненно, прямое сообщение. Разрез кембрия в данном структурно-фациальном районе сравнительно несложный. Он представлен глинистой толщей балтийской серии и залегающей на ней со значительным перерывом так наз. ижорской толщей предпола- 
гаемо средне-кембрийского возраста (Биркис и др., 1972). Мощность отложений не превышает здесь, как правило, $100-120$ м. В пределах этого района вполне возможна единая стратиграфическая схема, однако для ее разработки требуется в настоящее время основательное изучение строения ижорской толщи, отдельные уровни которой могут иметь раннекембрийский возраст (Янкаускас, 1973). Следует также уточнить взаимоотношение лонтоваской свиты Эстонии с молетской и алунтаской свитами Литвы и выяснить распространение здесь аналогов ровенских слоев Украины, наличие которых по акритархам установлено в скв. Лудза-15 (Биркис и др., 1972) и в скв. Вилькишкяй-68 (рис. 1, В). Типовыми разрезами для Восточно-Прибалтийского района могут служить керны скв. Лудза-15 в интервале 695-797 (кернохранилище Рига) и скв. Вилькишкяй-68 в интервале $260-355$ м (кернохранилище Вильнюс).

На стыке структурно-фациальных районов западнопо и восточного типов вырисовывается узкая субмеридиональная полоса, характеризующаяся сильно сокращенным разрезом кембрия и неясным стпатиграфическим положением здешних отложений. На кристаллическом фундаменте здесь непосредственно залегают маломошные $(22-33$ м) песчано-алевритовые отложения, среди котодых могут оказаться элементы раннекембрийского разреза Западно-Прибалтийского района, возможно, в виде отложений наиболее мелководных или даже прибрежных фациальных зон (лакайская свита по Т. Янкаускасу и Л. Пашкявичене, 1973). Однако не исключено, что эти отложения в какой-то своей части могут перейти по простиранию в «ижорскую толщу», в составе которой на востоке палеонтологически установлено наличие уровней верхнекембрийского возраста (Балашова, 1963). Поскольку палеонтологические находки в пределах рассматриваемой полосы почти отсутствуют, а литолого-минералогические критерии расчленения разреза разработаны еше слабо, то вопрос об отнесении данното участка к западному или восточному району остается открытым до проведения специальных исследований.

Восточная граница данной полосы отражает, очевидно, зону нарушений в фундаменте, по которой в раннем кембрии происходили тектонические движения двух соседних блоков. В результате этого западнее данной линии отложения балтийской серии, вероятно, не распространялись, а начиная с момента накопления верхней песчано-алевритовой («ижорской») толщи эти дифференциальные движения в осадконакоплении уже не отражались. Западная граница этой полосы проводится более условно, чем восточная, по исчезновению в разрезе типичных литологических подразделений (свит) Западно-Прибалтийского района (рис. 1, Б). На схеме районирования (рис. 3) эти границы показаны пунктиром.

Таким образом, выделенные два района для вендских и три района для кембрийских отложений могут вполне служить основой для разработки местных стратиграфических схем этой терригенной части разреза. Выявление фациальной зональности для более детального районирования территории в настоящее время осуществимо только по более коротким этапам развития, соответствуюшим по времени приблизительно продолжительности формирования отдельных свит. Однако учитывая, что синхронность границ терригенных свит почти всегда сомнительна, а сами объемы свит прибалтийского кембрия толкуются исследователями по-разному, то более подробное районирование территории по этому признаку вряд ли возможно на современном уровне изученности. Целесообразнее в первую очередь разработать местные схемы структурнофациальных зон до уровня однозначно интерпретируемых свит и только в тех случаях, где это возможно, дойти до уровня пачек. Для достижения 
этой первоочередной задачи в ближайшие годы необходимо решить ряд принщипиальных положений по стратипрафии вендо-кембрийских отложений всего региона, из которых мы считаем наиболее важными следуюшие вопросы.

По вендским отложениям следует разработать критерии для проведения границы между волынской и валдайской сериями на юго-востоке Литвы и выявить по всей Восточной Прибалтике возрастные соотноше. ния подразделений регрессивной фазы валдайского цикла осадконакопления (воронковская и вилькишкяйская свиты).

По кембрийским отложениям необходимо выяснить возраст и выработать критерии для расчленения разреза, залегающего ниже сакаских алевролитов в Запално-Прибалтийском районе; решить терминологические вопросы и выработать единую номенклатуру подразделений раннего кембрия этого района в целом, выяснив при этом соотношение курземских (курсаских) слоев с гегескими и вирбалисскими слоями юга Прибалтики; выяснить ранг и объем кибартайских слоев и разработать критерии для их однозначного выделения: изучить возможность расчленения дейменской серии на свиты и выработать номенклатуру для средне. верхнекембрийского разреза Западно-Прибалтийского района; изучить строение верхней песчано-алевоитовой («ижорской») толши центральных и восточных районов Прибалтики, выяснив возраст отдельных ее уровней и возможность расчленения этой толщи на свиты, а также разработать стратиграфическую номенклатуру для данной части разреза; уточнить распространение отложений ровенского возраста в Прибалтике.

\section{Л И ТЕ Р А Т Р А}

Бал а шо в а Е. А. 1963. Пепвая находка вепхнекембрийских трилобитов на Русской платформе. Вестник ЛГУ, сер. геол., № 12.

Биркис А. П., Брангулис А. П., Волкова Н. А.. Розанов А. Ю. 1970. Но. вые данные по стратиграфии кембрия Западной Латвии. ДАН СССР. 195. № 4

Би к и с А. П., Бр ангулис А. П.. Волков а Н. А., Роз а нов А. Ю. 1972. Новы данные по стратиграфии кембрия Восточной Латвин. ДАН СССР, 204, № 1.

Григялис А. А., Игн а та вич юс В. И. С ал а д ж ю В. Ю. 1971. Стратиграфические схемы и легенда геологических карт Литовской ССР. Вильнюс.

Каплан А. А., Андреев а О. Н. Чернышева Н. Е., Горянский В. Ю. 1973 Первая находка палеонтологически охарактеризованных верхнекембрийских отложений в Южной Прнбалтике. ДАН СССР, 209, № 6.

Каплан А. А.. Ф анд ер фли т Е. К.. Гор янск и й В. Ю., 1972. Кембрийские отложения Южной Прибалтики. Изв. АН СССР, сер, геол., № 6.

Л иелд иен а Э. К., Фрид ри хсоне А. Н. 1968. О стратиграфии кембрийских отложений Западной Латвии. В сб.: Стратиграфмя нижнего палеозоя Прибалтики и корреляция с другими регионами. Вильнюс.

М а рдл а А. К., М н нс К. А., Кал а Э. А.. К а к К. Ф., Э р ис а л у Э. К. 19є8. К стратиграфии кембрийских отложений Эстонии. В сб.: Стратиграфия нижнего палеозоя Прибалтики и корреляция с другими регионами. Вильнюс.

М е н К. А., Пи р р у с Э. А. 1971. О стратиграфин пограничных слоев венда и кембрия на северо-западе Русской платформы. Нзв. АН СССР, сер. геол., № 11 .

М н н К., П и р р у с Э. 1972. Новые данные о возрасте тискреских слоев по материалам северо-западных разрезов Эстонин. Изв. АН ЭССР, Хим, Геол., 21, № 3.

М янниль Р. М. 1966. История развития Балтийского бассейна в ордовике. Таллин. С аж а ла уск а с В. Ф. 1966. Новые данные по стратиграфичеокой схеме кембрийских отложений Южной Прибалтикн. Тезисы научн. студ. конф., Вильнюсский ГУ им. В. Капсукаса. Вильнюс.

С ак ал а у ск а с В. Ф. 1968. Новая стратиграфическая схема кембрийских отложений Южной Прибалтики. В сб:: Материалы V конф. геологов Прибалтики и Белоруссин. Внльнюс.

Я н к у ск а с Т. В. 1972. Біностратиграфия ннжнего кембрия Литвы (по акритархам) ДАН СССР, 205, № 5. 
Я нк а уска с Т. В. 1973. О составе акритарх ижорской свиты Русской платформы Материалы ІІІ научн. конф. геологов Литвы. Вильнюс.

Янкаускас Т. В., Пашкявичене Л. Т. 1973. Новые данные к стратиграфии кембрия восточных районов Литовской ССР. Материалы III научн, конф. геологов Литвы. Вильнюс.

Ннститут геологии
Академии наук Эстонской ССР
ВННИМОРГЕО (Рига)
Управление геологии Совета Министров
Эстонской ССР
Управление геологии Совета Министров
Латвийской ССР
Управление геологии Совета Министров
Литовской ССР

Поступила в редакцню $16 / 1 \quad 1974$

A. BRANGULIS, E. KALA, A. MARDLA, Kaisa MENS, E. PIRRUS,

V. SAKALAUSKAS, Aria FRIDRICHSONE, T. JANKAUSKAS

\section{BALTIKUMI VENDI JA KAMBRIUMI STRUKTUURILIS-FATSIAALSE RAJONEERIMISE SKEEM}

Nõukogude Baltikumi geoloogiline areng vendi ja kambriumi kestel on olnud võrdlemisi keerukas: setete kuhjumine on siin toimunud mitmete erisuunaliste transgressioonide tingimustes, ning sellest tingitult erineva struktuuri järgi paigutunud veekogudes. Selle territooriumi üksikud osad on pikemat aega olnud kontinentaalseteks ala. deks, kus toimus varem kuhjunud setete murenemine ja ärakanne. Seepärast tuleb kohalike stratigraafiliste skeemide mōjusfääri määramiseks kōnesoleval territooriumil lähtuda esmajoones kõrgeimat järku fatsiaalsuse tunnusest, s. o. setete kuhjumise ja kulutusalade vastastikusest paigutusest, ehk teiste sonnadega, säilinud läbilōigete stratigraafilisest terviklikkusest (joon. 1). Basseinisisesed fatsiaalsed muutused on detailsemaks rajoneerimiseks kasutatavad üksnes ajastust väiksemate ajalōikude puhul. Sellegi teostamine aga on väga raske, sest läbilōikeid on uuritud veel ebaühtlaselt.

Seniste uurimistulemuste alusel vōib väita, et vendi ajal jaotus Baltikumi ter. ritoorium kahte rajooni (joon. 2). Läänepoolses vendi setted peaaegu puuduvad, idapoolses levivad aga pidevalt ja on liigestatavad ühtse stratigraafilise skeemi järgi (joon. 1).

Kambriumiajastul on võimalik eristada kolm rajooni (joon. 3): läänepoolses algas setete kuhjumine alates varakambriumi teisest poolest, idapoolses toimus see pőhiliselt varakambriumi esimesel poolel ja jätkus hiljem vaid väga piiratult. Põhja-Baltikumis mōlema mainitud rajooni arengujooned osaliselt pōimuvad, mistōttu setete kuhjumine on siin kogu varakambriumi kestel toimunud peaaegu pidevalt, kusjuures puuduvad üksnes selle ajastiku noorimad kihid.

Ida- ja läänerajoonide vahele jääb kitsas üleminekuvöönd (Läti, Leedu), mille struktuurilis-fatsiaalne asend naaberrajoonide suhtes pole praegu veel selge.

\section{A. BRANGULIS, E. KALA, A. MARDLA, Kaisa MENS, E. PIRRUS, \\ V. SAKALAUSKAS, Aria FRIDRICHSONE, T. JANKAUSKAS}

\section{STRUCTURAL FACIAL SCHEME OF THE EAST BALTIC IN THE VENDIAN AND CAMBRIAN}

Structural facial distinction was carried out in order to find out the number and the range of influence of local stratigraphic schemes.

The geological development of the East-Baltic territory was relatively complicated in the Vendian and Cambrian. Sedimentation proceeded in basins of a different structural plan, whereas some parts of the territory were uplifted and from time to time subjected to weathering and erosion.

According to this, we started from the characteristics of the main facial division: the mutual position of sedimentation and denudation, i.e. we kept to the stratigraphic completeness of the sequences (Fig. 1). Apart from these main facial divisions on 
the territory of a single basin, we can trace a secondary facial zonality for shorter units of time than a period. But even in this case it was hard work because of the insufficient knowledge of incomplete sections, at the time being.

We took into account the above-mentioned specifications and divided the EastBaltic Vendian territory into 2 districts (Fig. 2). In the western district the Vendian deposits are nearly missing, whereas in the eastern part they have a wide-spread occurrence and can be divided after a uniform stratigraphic scheme.

In the Cambrian the East-Baltic area is divided into three districts (Fig. 3). The first of them is placed in the northern part of the East Baltic as a zone of an E-W orientation, where the accumulation of sediments proceeded in the first half of the Early Cambrian (Preterilobite time), with a structural plan similar to the Vendian. At the beginning of the middle of the given time (Holmian Series), this district was a part of the western sedimentation basin (Fig. 1, A).

The two other districts have a submeridional orientation. In the western district sedimentation started in the second half of the Early Cambrian and continued during the rest of the period (Figs. 1,5 and $B$ ), including the Late Cambrian (only in the south-western part).

In contrary to the western district, the eastern one is characterized by a wide distribution of deposits of the lowermost Early Cambrian; the younger units have here a very limited distribution. A narrow transition zone ranges between the indicated districts, whose structural facial position in relation to the two adjoining districts is not clear at this stage of research. 